\title{
Rancang Bangun Aplikasi Pelaporan Kerusakan Sarana dan Prasarana Fasilitas Mahasiswa Berbasis Android
}

\author{
Tri Sugihartono ${ }^{1}$, Sarwindah $^{2}$, Marini $^{3}$, Fernandy Ricardo Antonius ${ }^{4}$ \\ ${ }^{1,4}$ Program Studi Teknik Informatika, ${ }^{2}$ Program Studi Bisnis Digital, \\ ${ }^{3}$ Program Studi Sistem Informasi \\ ${ }^{1,2,3,4}$ ISB Atma Luhur, Indonesia, Jl. Sudirman, Kel. Selindung, Pangkalpinang \\ Email : trisugihartono@atmaluhur.ac.id ${ }^{1}$,indah_syifa@atmaluhur.ac.id ${ }^{2}$, \\ arinimarini44@atmaluhur.ac.id ${ }^{3}, 1711500123 @$ mahasiswa.atmaluhur.ac.id $^{4}$
}

\begin{abstract}
ABSTRAK
Perkembangan Teknologi informasi adalah suatu hal yang sangat penting yang dapat digunakan sebagai sebuah sistem terkomputerisasi yang diharapkan dapat membantu kemudahan untk mendapatkan informasi dengan cepat, akurat dan efisien., pada suatu institusi Pendidikan sangat diperlukan adanya kenyamanan yang di dukung oleh sarana dan prasarana dengan keadaan yang baik. Karena saat ini proses pelaporan erusakannya menggunakan kotak saran (manual), sangat sedikit sekali dan sangat tida efisien nya proses pelaporannya, sehingga ketika ada fasilitas digunakan masih ditemukan kerusaan dari fasilitas kampus. oleh karena itu dalam penelitian ini merancang dan membangun aplikasi pelaporan kerusaan sarana dan prasarana yang digunakan oleh mahasiswa, staff, dan dosen. Tujuan dari penelitian ini adalah untuk mengatasi permasalahan yang ada dan mempermudah komunikasi untuk pelaporan erusakan saran dan prasarana kepada bagian terkait. Penelitian ini menggunakan model Prototype. Hasil dari penelitian ini adalah dengan adanya aplikasi pelaporan ini, permasalahan terkait dengan kerusakan sarana dan prasarana dapat diatasi dengan cepat dengan efektif dan cepatnya proses komunikasi antara mahasiswa, dosen, serta staff kepada Bagian Administrasi dan Umum
\end{abstract}

Kata Kunci : Pelaporan, Kerusakan, Sarana, Prasarana, Android

\section{ABSTRACT}

The development of information technology is a very important thing that can be used as a computerized system which is expected to help make it easier to get information quickly, accurately and efficiently. good. Because currently the damage reporting process uses a suggestion box (manual), there is very little and the reporting process is very inefficient, so that when a facility is used, damage is still found from campus facilities. Therefore, in this study, design and build an application for reporting damage to facilities and infrastructure used by students, staff, and lecturers. The purpose of this study is to overcome existing problems and facilitate communication for reporting damage to suggestions and infrastructure to the relevant department. This research uses the prototype model. The results of this study are that with this reporting application, problems related to damage to facilities and infrastructure can be overcome quickly with an effective and fast communication process between students, lecturers, and staff to the Administration and General Affairs.

Keywords: Reporting, Damage, Facilities, Infrastructure, Android 


\section{PENDAHULUAN}

Perkembangan teknologi informasi adalah suatu hal yang sangat penting yang dapat digunakan sebagai sebuah sistem terkomputerisasi yang diharapkan dapat membantu kemudahan (Alkadri \& Insani, 2019) untuk mendapatkan informasi dengan cepat(Afrizal \& Apriadi, 2020)(Rohmah \& Eriyanto, 2020), akurat (Simanjuntak et al., 2019)dan efisien(Sugihartono Rendy Rian Chrisna Putra, 2019)(Wella \& Fauzan, 2016).

Pada Perguruan Tinggi untuk mensukseskan pembelajaran mahasiswa diperlukan adanya kenyamanan yang didukung oleh sarana dan prasarana dengan keadaan yang baik. Maka dari itu pada Institut Sains Dan Bisnis Atma Luhur telah terdapat berbagai fasilitas sarana dan prasarana yang mendukung perkuliahan. Sarana dan prasarana yang disediakan memiliki masa pemakaian yang berbeda-beda, oleh karena itu tidak heran terdapatnya sarana dan prasarana yang mengalami kerusakan sehingga menganggu proses pembelajaran (Natda, 2013).

Pada Institut Sains Dan Bisnis Atma Luhur pelaporan kerusakan pada sarana dan prasarana masih dilakukan dengan cara manual. Apabila terjadinya kerusakan sarana dan prasarana mahasiswa menyampaikan laporannya dengan menulis surat yang diletakkan pada kotak saran yang ada, dan mahasiswa harus menemui langsung petugas Bagian Administrasi Umum untuk melaporkan terjadinya kerusakan sarana dan prasarana yang ada. Namun, dengan cara tersebut sangatlah kurang efektif dilakukan karena kotak sarang sangatlah jarang dilirik oleh mata ataupun petugas dan juga terkadang laporan yang disampaikan memerlukan penanganan yang membutuhkan waktu lama.

Dari permasalahan tersebut disertai dengan perkembangan teknologi saat ini, maka sangat diperlukannya sebuah aplikasi untuk admin atau petugas Bagian Administrasi Umum Institut Sains Dan Bisnis Atma Luhur yang digunakan untuk proses pembelajaran agar berjalan dengan nyaman(Maulidiansyah et al., 2017) dan baik tanpa adanya kendala(Alkadri \& Insani, 2019).

\section{METODE PENELITIAN}

Dalam melakukan pengembangan perangkat lunak ini menggunakan model penelitian pengembangan sistem yaitu Prototype (Ferdiansyah1 et al., 2016). 


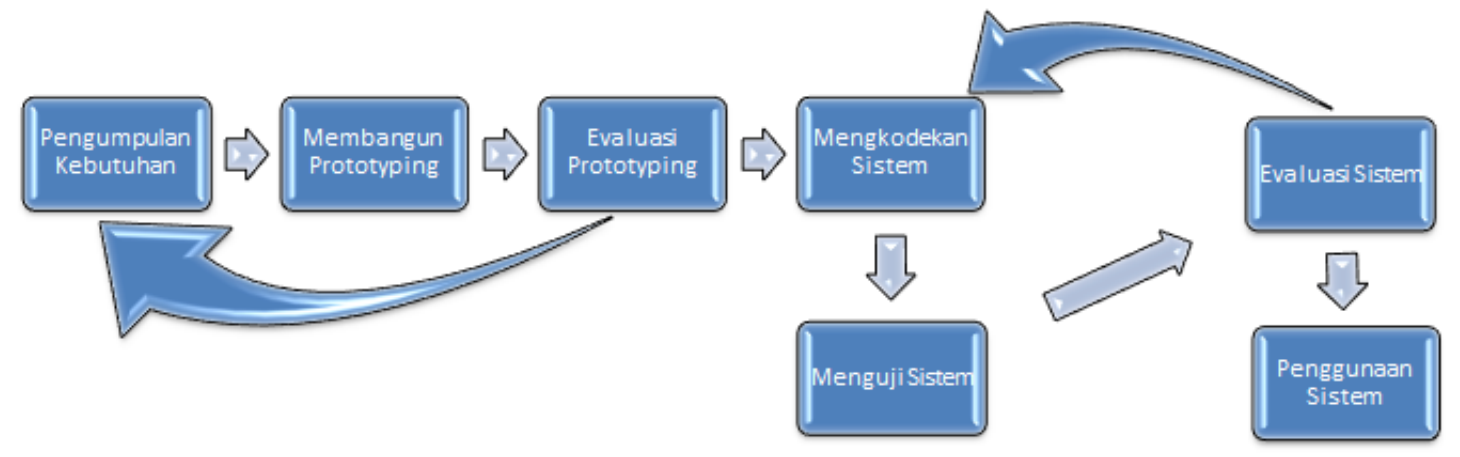

Gambar 1: Metode Prototype

Berikut ini adalah tahapan-tahapan dan penjelasan pengembangan sistem menggunakan model prototype:

1. Pengumpulan Kebutuhan (Afrizal \& Apriadi, 2020)

Pada tahapan ini pengumpulan kebutuhan dilakukan dengan melakukan proses pengambilan data di Bagian Administrasi Umum (BAU) untuk menspefikasikan kebutuhan perangkat lunak dan mengajukan beberapa pertanyaan apa yang diperlukan, ini dilakukan agar dapat dipahami apa yang dibutuhkan oleh $u s e r$.

\section{Membangun Prototype}

Pada tahapan ini dilakukannya proses membangun prototype desain perangkat lunak dengan membuat perancangan desain sementara program perangkat lunak untuk diperlihatkan kepada user(Rahmatuloh et al., 2019).

\section{Evaluasi Prototype}

Pada tahapan ini dilakukan oleh user apakah prototype yang sudah dibangun sudah sesuai dengan keinginan user. Jika sudah sesuai maka pembuat akan melanjutkan ke proses tahapan selanjutnya. Jika belum sesuai maka akan dilakukan perbaikanperbaikan yang diperlukan(Hermansyah et al., 2017). 
4. Mengkodekan Sistem

Pada tahapan ini prototype yang sudah disetujui dan disepakati bersama, selanjutnya dilakukan pengkodean program ke dalam bahasa pemrograman yang sesuai(Purnomo et al., 2019).

\section{Menguji Sistem}

Pada tahapan ini setelah sistem menjadi suatu perangkat lunak yang bisa dipakai, dilakukan pengujian yang berfokus pada perangkat lunak dari segi logika dan fungsional serta memastikan kembali bahwa semua bagian sudah dilakukan pengujian. Hali ini dilakukan untuk mengurangi kesalahan dan untuk memastikan keluaran yang dihasilkan sesuai dengan keinginan user.

\section{Evaluasi Sistem}

Pada tahapan ini user akan melakukan evaluasi kepada sistem yang sudah jadi apakah sudah sesuai dengan apa yang diinginkan. Jika sudah maka akan dilakukan langkan selanjutnya.

\section{Menggunakan Sistem}

Pada tahapan ini perangkat lunak yang telah dilakukan pengujian dan diterima oleh user, maka perangkat lunak siap untuk digunakan sesuai dengan kebutuhan user.

\section{HASIL DAN PEMBAHASAN}

\subsection{Perancangan Sistem}

1. Usecase Diagram

Usecase diagram dipergunakan untuk meggambarkan kebutuhan serta fungsionali s dari sistem. Berikut ini adalah usecase diagram dari penelitian sebagai berikut: 


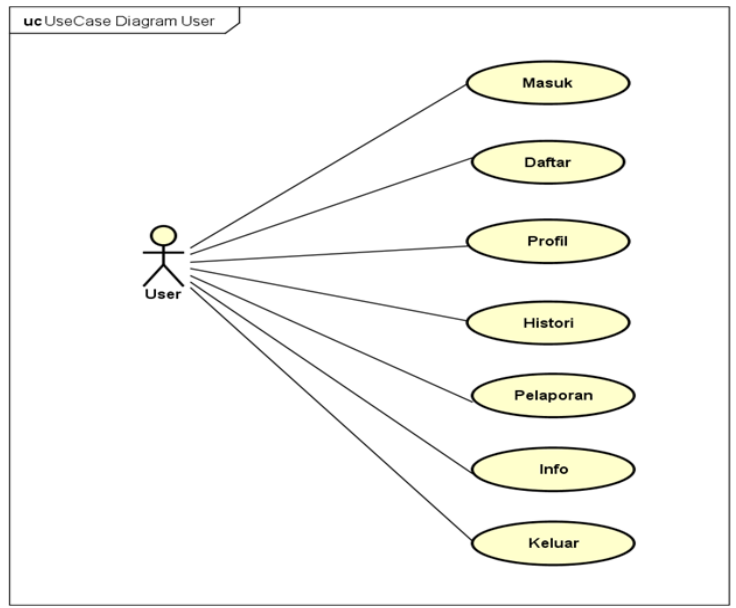

Gambar 2: Usecase Diagram User

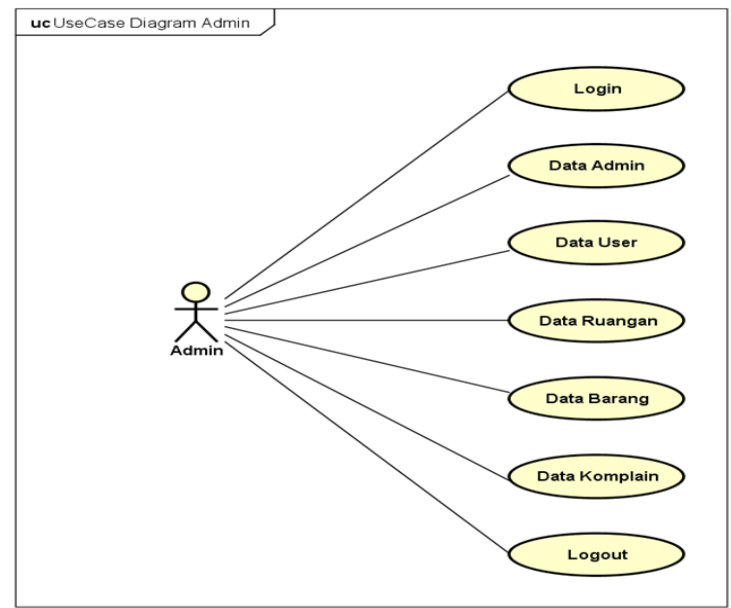

Gambar 3: Usecase Diagram Admin

\section{Class Diagram}

Class diagram menggambarkan struktur statis dari kelas dalam sistem dan mengg ambarkan atribut, operasi dan hubungan antar class. Berikut ini adalah class diagram da ri penelitian ini sebagai berikut: 


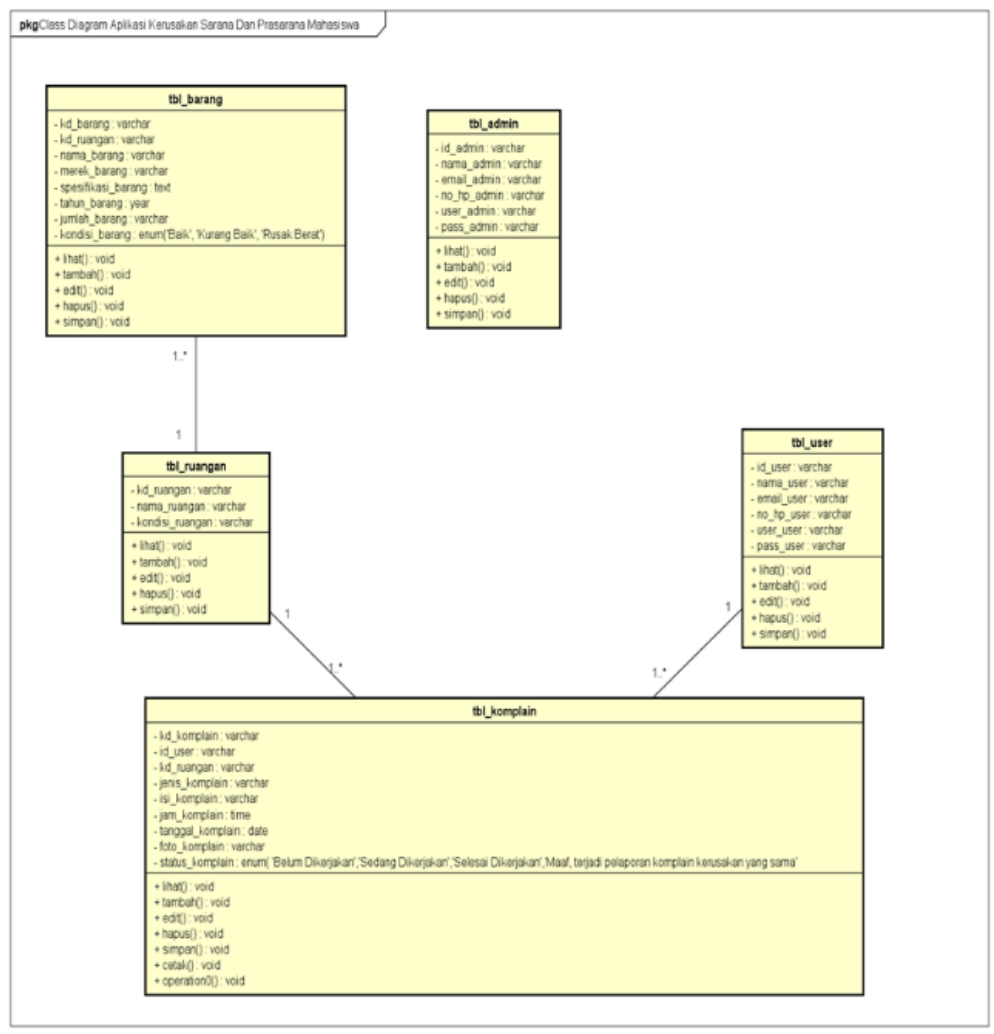

Gambar 4: Class Diagram Aplikasi Pelaporan Kerusakan

\subsection{Implementasi}

1. User

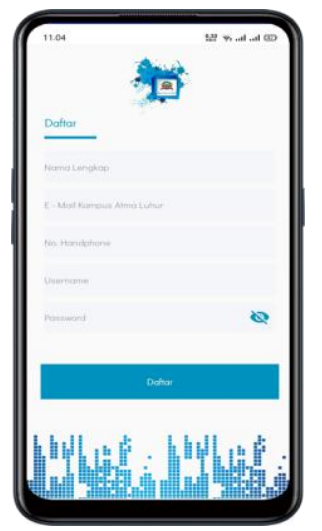

Gambar 5 Tampilan Layar Daftar

Pada gambar 5 menggambarkan bagaimana user harus membuat akun terlebih dahulu a gar bisa masuk ke sistem. 


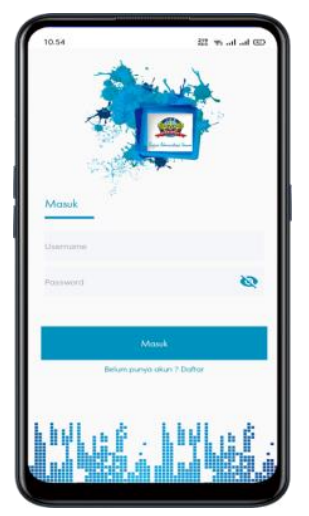

Gambar 6 Tampilan Layar Masuk

Pada gambar 6 menggambarkan bagaimana ketika pertama kali user akan masuk ke sist em.

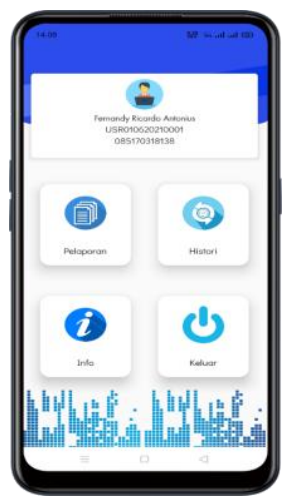

\section{Gambar 7 Tampilan Layar Menu Utama}

Pada gambar 7 menggambarkan bagaimana tampilan halaman utama ketika berhasil ma suk disistem.

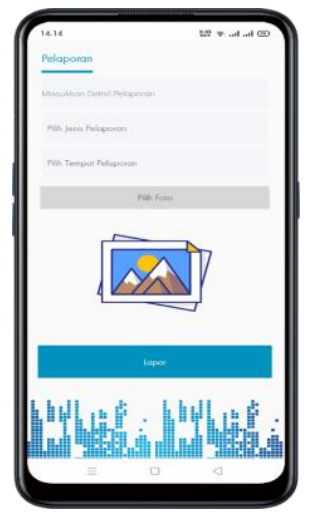

Gambar 8 Tampilan Layar Pelaporan

Pada gambar 8 menggambarkan tampilan yang digunakan untuk melakukan pelaporan $\mathrm{k}$ erusakan sarana dan prasarana mahasiswa. 


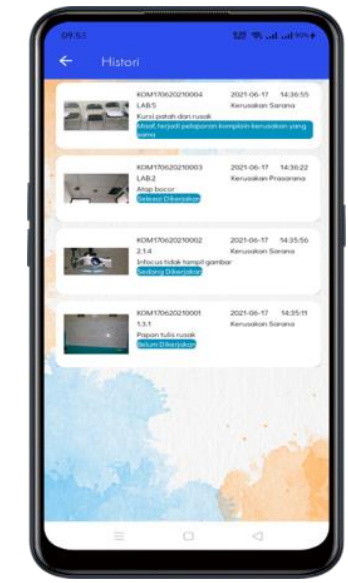

Gambar 9. Tampilan Layar Histori

Pada gambar 9 menggambarkan bagaimana tampilan dari histori pelaporan yang telah di laporkan oleh user.

\section{Admin}

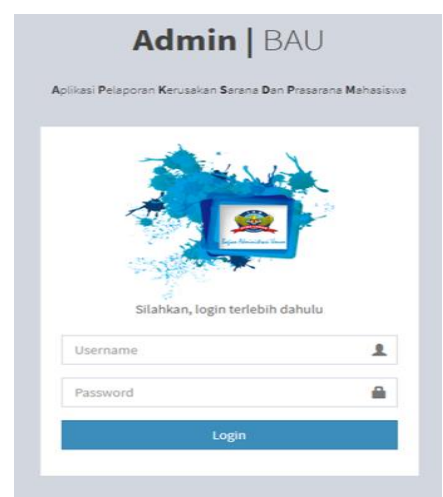

Gambar 10 Tampilan Layar Login

Pada gambar 10 menggambarkan bagaimana tampilan awal jika admin ingin masuk ke s istem. 


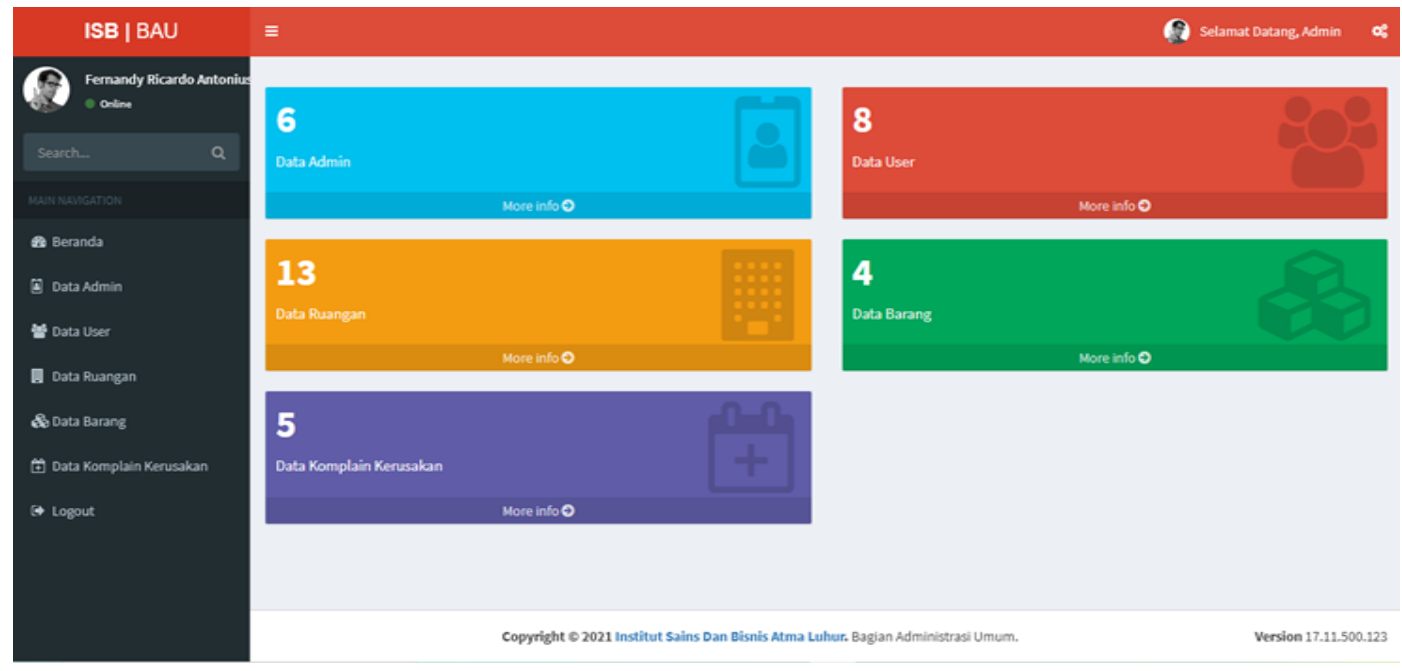

Gambar 11 Tampilan Layar Beranda

Pada gambar 11 menggambarkan setelah admin login ke ystem akan masuk ke tampil an halaman utama dari ystem.

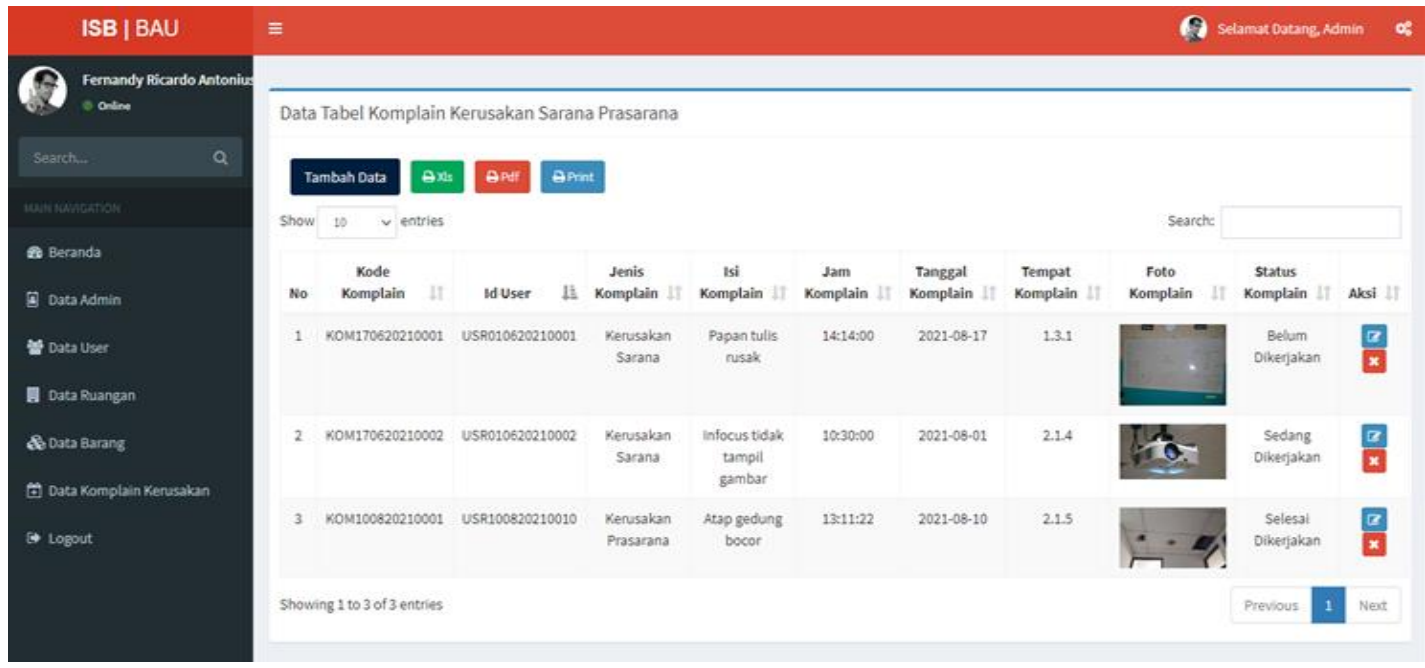

Gambar 12 Tampilan Layar Data Komplain

Pada gambar 12 dipergunakan untuk menambahkan, mengedit, menghapus, mencetak se rta merubah status komplain data komplain kerusakan yang sebelumnya telah diinput pa da aplikasi android. 


\section{SIMPULAN}

Berdasarkan uraian dan hasil analisa yang telah dilakukan selama pengerjaan pembuatan Aplikasi Pelaporan Kerusakan Sarana Dan Prasarana Mahasiswa Pada Institut Sains Dan Bisnis Atma Luhur Berbasis Android, maka dapat diambil kesimpulan bahwa melalui perancangan, membangun, mengembangkan serta mengimplementasikan penelitian ini membuktikan bahwa aplikasi ini dapat membantu dan mempermudahkan mahasiswa dalam melakukan pelaporan kerusakan sarana dan prasarana yang terjadi di dalam ruang kelas dengan mudah dan lebih cepat.

\section{DAFTAR PUSTAKA}

Afrizal, A. S., \& Apriadi. (2020). Rancang Bangun Aplikasi Service Elektronik Berbasis Mobile Di Kabupaten Musi Banyuasin. Jurnal Teknologi Informasi Dan Komputer Politeknik Sekayu, 10(1), 13-19.

Alkadri, S. P. A., \& Insani, R. W. S. (2019). Rancang Bangun Aplikasi Pelaporan Kekerasan Terhadap Perempuan dan Anak pada DPPPA Provinsi Kalimantan Barat. Jurnal Edukasi Dan Penelitian Informatika (JEPIN), 5(3), 329. https://doi.org/10.26418/jp.v5i3.36003

Ferdiansyah1, M. S., Jasri., M., 2, \& Widjianto3. (2016). Aplikasi Quick Response Dalam Melayani Pengaduan Kerusakan Sarana Stt Nurul Jadid Berbasis Android Dan Web. Prosiding SENTIA, 8(Muhammad Soleh Ferdiansyah1, Mohammad Jasri. 2 , Widjianto3), 152-157. https://prosiding.polinema.ac.id/sentia/index.php/SENTIA2016/article/viewFile/3 $2 / 27$

Hermansyah, Y., Lazuardi, L., \& Hasan Basri, M. (2017). Efektivitas penerapan aplikasi m-health untuk posyandu di Puskesmas Kembang Seri Kabupaten Bengkulu Tengah. Journal of Information Systems for Public Health, 2(1), 57-67. https://journal.ugm.ac.id/jisph/article/view/11240

Maulidiansyah, R., Rakhman, D. F., \& Ramdhani, M. A. (2017). Aplikasi Pelaporan Kerusakan Jalan Tol Menggunakan Layanan Web Service Berbasis Android. Jurnal ISTEK, 10(1), 117-123.

Natda, K. V. (2013). Responsive Web Design. Eduvantage, 1(1), 308-315. https://doi.org/10.11635/2319-9954/1/1/18

Purnomo, A. M., Priyambadha, B., \& Kharisma, P. A. (2019). Pengembangan Aplikasi Mobile Pelaporan Keluhan Pelanggan PDAM Menggunakan Fitur Geotagging Berbasis Android (Studi Kasus: PDAM Tirta Tuah Benua Kutai Timur). Jurnal Pengembangan Teknologi Informasi Dan Ilmu Komputer E-ISSN:2548-964X Vol.3, NO, 4, April 2019,Hlm.3498-3504, 3(4), 3498-3504. http://j-ptiik.ub.ac.id

Rahmatuloh, M., Nirwan, S., \& Mauludy, R. (2019). Rancang bangun aplikasi pengelolaan sarana dan prasarana di Kantor Pos Cimahi 40500 berbasis web. 
Teknik Informatika, 11, 1-8.

Rohmah, M., \& Eriyanto, N. (2020). PENERAPAN APLIKASI MOBILE UNTUK PELAPORAN KINERJA PEGAWAI DALAM MENDUKUNG eGOVERNMENT. Jurnal PIKOM (Penelitian Komunikasi Dan Pembangunan), 21(1), 27. https://doi.org/10.31346/jpikom.v21i1.2481

Simanjuntak, R. H., Tolle, H., \& Dewi, R. K. (2019). Pengembangan Aplikasi Mobile Geotagging Fasilitas Tanggap Darurat Bencana Alam Menggunakan Algoritma Polylines sebagai Pencarian Rute Terdekat. ... Informasi Dan Ilmu Komputer e ..., 3(9), 8964-8971. http://j-ptiik.ub.ac.id/index.php/j-ptiik/article/view/6315

Sugihartono Rendy Rian Chrisna Putra, T. (2019). SATIN - Sains dan Teknologi Informasi Pengembangan Aplikasi E-Government Pelayanan Administrasi Terpadu. SATIN - Sains Dan Teknologi Informasi Journal, 5(2).

Wella, W., \& Fauzan, F. H. (2016). Rancang Bangun Aplikasi Mobile Sistem Pelaporan Keberangkatan Pesawat. Jurnal ULTIMA InfoSys, 7(2), 81-85. https://doi.org/10.31937/si.v7i2.544 